\title{
Experimental Research of the Influence of Hot Machining Method on AISI 4340 Lathe Machine Process Towards Specific Cutting Energy and Surface Roughness
}

\author{
Ismail $\mathrm{T}^{1, *}$ Dyos $\mathrm{S}^{1}$ Joni $\mathrm{Y}^{1}$ Samuel $\mathrm{S}^{1}$ Abdurahman $\mathrm{W}^{1}$ Aldi $\mathrm{Y}^{1}$ \\ ${ }^{1}$ Mechanical Engineering, Engineering Faculty of Sriwijaya University, Palembang, Indonesia \\ *Corrresponding author. Email: ismailthamrin@ft.unsri.ac.id
}

\begin{abstract}
.
This research is about the experimental investigation of AISI 4340 turning process using carbide tools with hot machining and dry cutting methods. The workpiece is heated using torch flame gas. Experimental analysis is held at various machining conditions for hot machining and dry cutting methods by focusing on the measuring specific cutting energy. The calculation of specific cutting energy is carried out theoretically. The purpose of this research is to observe the effect of various machining process conditions of the workpiece on specific cutting energy of the workpiece. This research also analyzed the effect of specific cutting energy on the surface roughness of the workpiece based on machining parameters after machining. The results showed that the feeding rate was the most influencing factor in determining the value of surface roughness and specific cutting energy. Based on the comparison between hot machining and dry cutting, hot machining provides a lower value of specific cutting energy than dry cutting.
\end{abstract}

Keywords: hot machining, dry cutting, surface roughness, specific cutting energy

\section{INTRODUCTION}

One of the research objectives in the machining process is to process metal materials that are difficult to cut at a cost and time in a short and precise manner. In other words, the good machining results of a material can be characterized by a low level of tool breakage, fast material removal rate, low specific cutting energy and low usage of machining power [1].

Specific energy in turning process is the ratio between the energy consumption used in the machining process, to the volume of the removal material of workpiece. The specific energy in the turning process is influenced by the cutting speed, cutting force, and speed of producing the removal material. In addition, this specific cutting energy is usually used to count the efficiency of energy of the machining process [2].

In the lathe machining process, surface roughness is an important factor that must be considered, especially for workpieces whose surfaces are touching and rubbing together. The surface roughness of a machining surface product can affect several functions, including surface friction, heat transfer, lubrication dispersion capability [3].

Working without the use of cutting fluids is an important goal in the industry to reduce production costs and environmental pollution. Dry machining is a machining process where the coolant is not used in the turning process. Apart from dry machining, there is a method of machining where the coolant is not used, namely in hot machining. The basic principle behind this process is that the surface of the workpiece to be worked is heated to a temperature below recrystallization. With this heating, the shear forces are reduced and the machining process is made easy. During the machining process, instead of improving the quality of the cutting material, softening the workpiece is an alternative [4].

Therefore it is necessary to research the turning process, especially regarding the effect of changes in lathe machining parameters, on how much specific cutting energy and roughness is generated from the lathe machining process using hot machining and dry cutting methods. 


\section{METHODOLOGY}

This research using AISI 4340 as a workpiece. These workpieces are used in the manufacturing industry where high tensile strength and yield strength are required. Components made of AISI 4340 steel are widely used in the aircraft, automotive, and general engineering industries, for example, shafts, and others auto parts.[5]. The AISI 4340 is turned using a carbide tool.

The hot machining method is used to heat the workpiece before turning it according to predetermined parameters. In this case, the gas torch is used to heat the workpiece because it is easy to use, has an economical price, the flame size setting, and the flame spray valve can be adjusted making it easier to heat the workpiece to a predetermined temperature according to the machining conditions

The parameters used in this research are feed rate, cutting speed, , and heating temperature. The test parameters to be calculated are the surface roughness and the specific cutting energy and. Specific energy calculations are carried out theoretically. Handysurf Accretech E-35B waseasure the surface roughness of the AISI 4340.

\subsection{Cutting Force}

To get the specific cutting energy value, we must first obtain the cutting force value. To get the value of the cutting force, we need to find the ratio value of the thickness of the chip, the angle of shear, the angle of friction, and the shear force. These values can be obtained using the following formulas based on [6].

Chip thickness ratio:

$r=\frac{h_{2}}{n_{r}}$

Where $\quad h=$ thickness before cutting $(\mathrm{mm})$

$h_{e}=$ thickness after cutting $(\mathrm{mm})$

Shear angle formula $(\phi)$ :

$\tan \phi=\frac{r \cos \alpha}{1-\sin \alpha}$

The formula for the angle of friction $(\beta)$ :

$2 \phi+\beta-\alpha=90$

where, $\quad \alpha=$ rake angle $\left({ }^{\circ}\right)$

$\beta=$ angle of friction $\left({ }^{\circ}\right)$

$\phi=$ shear angle $\left(^{\circ}\right)$

Shear force formula $\left(F_{s}\right)$

$F_{g}=$ shear strength $x A$

$A=\frac{f a}{\sin \phi}$

where $\quad F s=$ shear force $(\mathrm{N})$

$\mathrm{A}=$ cross-sectional area $(\mathrm{mm})$

$\mathrm{f}=$ feed rate $(\mathrm{mm} / \mathrm{rev})$

$\mathrm{a}=$ depth of cut $(\mathrm{mm})$
In the book [6] An alternative way of determining the value of shear strength if the value is not known can be estimated by using the formula $S=(0.7)$ TS (Tensile strength). The tensile strength value is obtained by performing a tensile test. Tensile testing is carried out at each workpiece temperature. To get the cutting force value:

$F_{c}=\frac{F_{S} \cos (\beta+\alpha)}{\cos (\phi+\beta-\alpha)}$

\subsection{Specific Cutting Energy}

Specific cutting energy is the comparison between the consumption of energy used in machining process to the volume of workpiece wasted. To calculate the energy consumption $(\mathrm{Pm})$ includes the part of cutting force $(\mathrm{Fc})$, in the same direction of the cutting speed $(\mathrm{Vc})$. This is shown in equation (7). Next to find the specific energy of cutting, namely the comparison between energy consumption in machining operation $(\mathrm{Pm})$ with the rate material removal $(\mathrm{Z})$, as shown in equation (8).

$P_{\mathrm{m}}=F_{c} V_{c}$

$P_{s}=\frac{P_{m z}}{z}=\frac{F_{c} V_{c}}{f \backsim V_{c}}=\frac{F_{c}}{f a}$

where, $\quad$ Ps $=$ specific cutting energy $(\mathrm{Nm} / \mathrm{min})$

Pm $=$ energy used $(\mathrm{J})$

$\mathrm{Fc}=$ cutting force $(\mathrm{N})$

$\mathrm{Vc}=$ cutting speed $(\mathrm{m} / \mathrm{min})$

\section{RESULT AND DISCUSSION}

From the overall test results that have been carried out, the best results for the lowest specific cutting energy value are in the 8 th specimen with variations in cutting speed of $150 \mathrm{~m} / \mathrm{min}$, feeding motion $0.14 \mathrm{~mm} /$ rev, depth of cut $0.5 \mathrm{~mm}$, and heating temperature of $200^{\circ} \mathrm{C}$. Here are the results of the whole test.

Table 1. Specific Cutting Energy

\begin{tabular}{cccccc}
\hline No. & $\mathbf{V c}$ & $\mathbf{f}$ & $\mathbf{a}$ & $\mathbf{T}$ & $\mathbf{F s}$ \\
\hline 1 & 100 & 0.035 & 0.5 & 100 & 3.499311 \\
2 & 150 & 0.035 & 0.5 & 100 & 2.766298 \\
3 & 100 & 0.14 & 0.5 & 100 & 2.01855 \\
4 & 150 & 0.14 & 0.5 & 100 & 2.248768 \\
5 & 100 & 0.035 & 0.5 & 200 & 3.28386 \\
6 & 150 & 0.035 & 0.5 & 200 & 5,614744 \\
7 & 100 & 0.14 & 0.5 & 200 & 1.467738 \\
8 & 150 & 0.14 & 0.5 & 200 & 1.391188 \\
9 & 100 & 0.0875 & 1 & 150 & 3.021161 \\
10 & 150 & 0.0875 & 1 & 150 & 7.849686 \\
11 & 125 & 0.0875 & 1 & 150 & 2.450045 \\
12 & 100 & 0.035 & 0.5 & 24 & 23.35256 \\
13 & 150 & 0.035 & 0.5 & 24 & 23.1132 \\
14 & 100 & 0.14 & 0.5 & 24 & 7.587525 \\
15 & 150 & 0.14 & 0.5 & 24 & 2,96769 \\
16 & 100 & 0.0875 & 1 & 24 & 11.84682 \\
17 & 150 & 0.0875 & 1 & 24 & 4.13644 \\
\hline
\end{tabular}




\begin{tabular}{llllll}
\hline 18 & 125 & 0.0875 & 1 & 24 & 7.245128 \\
\hline
\end{tabular}

\subsection{Feed Rate Against Specific Cutting Energy}

In the graph of cutting speed of $100 \mathrm{~m} / \mathrm{min}$ with a depth of cut of $0.5 \mathrm{~mm}$, we can see that the greater the feeding rate (f), the smaller the specific cutting energy. Likewise with the cutting speed of $150 \mathrm{~m} / \mathrm{min}$, the greater the feed rate (f), the smaller the specific cutting energy. The smaller the specific cutting energy value, the better the workability of the material, in this research the cutting specific energy value with the smallest value was obtained from high feeding motion, $0.14 \mathrm{~mm} / \mathrm{rev}$.

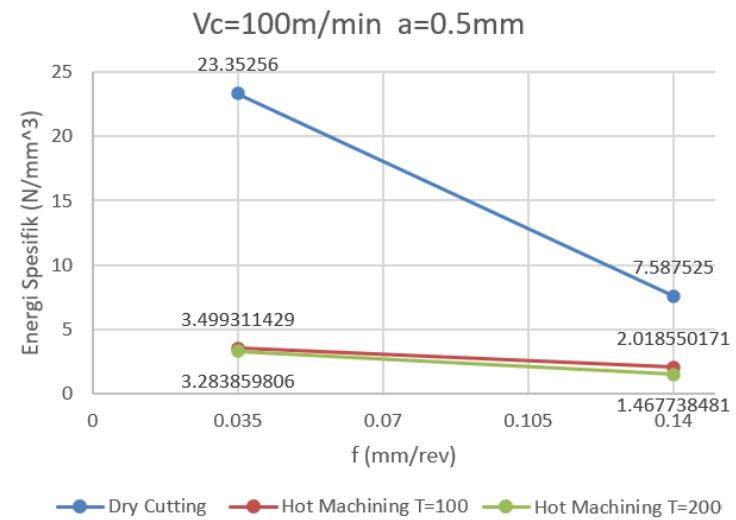

Figure 1. The graph of the ratio of specific cutting energy to feed rate (f) with Vc $100 \mathrm{~m} / \mathrm{min}$ and depth of cut $0.5 \mathrm{~mm}$.

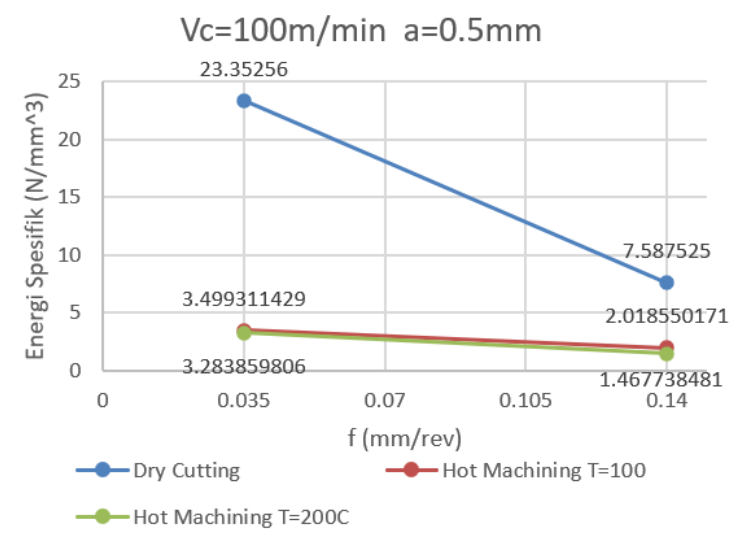

Figure 2. The graph of the ratio of specific cutting energy to feed rate (f) with Vc $100 \mathrm{~m} / \mathrm{min}$ and depth of cut $0.5 \mathrm{~mm}$.

From the two graphs above we can see that the effect of feeding motion is inversely proportional to the specific energy of cutting. In the research conducted [7], low feed rate shows a high specific cutting energy because ploughing and rubbing dominate the mechanical process, whereas at higher feed motion shearing predominates which represents a lower specific cutting energy and an efficient cutting process.

\subsection{Cutting Speed Against Specific Cutting Energy}

A feed rate of $0.035 \mathrm{~m} / \mathrm{rev}$, and a depth of cut $0.5 \mathrm{~mm}$, the graph shows that the greater the cutting speed, the smaller the specific cutting energy obtained, but in hot machining conditions with a heating temperature of $200^{\circ} \mathrm{C}$. The graph shows an increase of cutting speed, will increase the specific energy of cutting.

Likewise at $0.14 \mathrm{~mm} / \mathrm{rev}$ feed rate and $0.5 \mathrm{~mm}$ depth of cut, the graph also shows the greater the cutting speed, the smaller the specific cutting energy. But in hot machining conditions with a heating temperature of $100^{\circ} \mathrm{C}$, the graph shows a slight increase in value. cutting specific energy as the cutting speed increases.

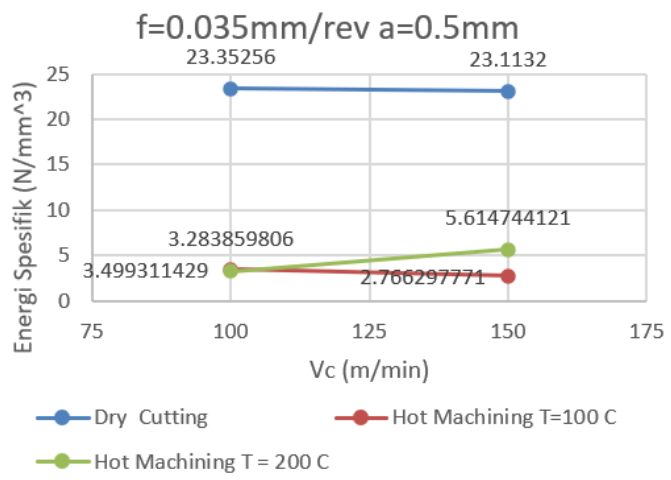

Figure 3. Graph of cutting specific energy to cutting speed with a feed rate of $0.035 \mathrm{~mm} / \mathrm{rev}$ and depth of cut of $0.5 \mathrm{~mm}$

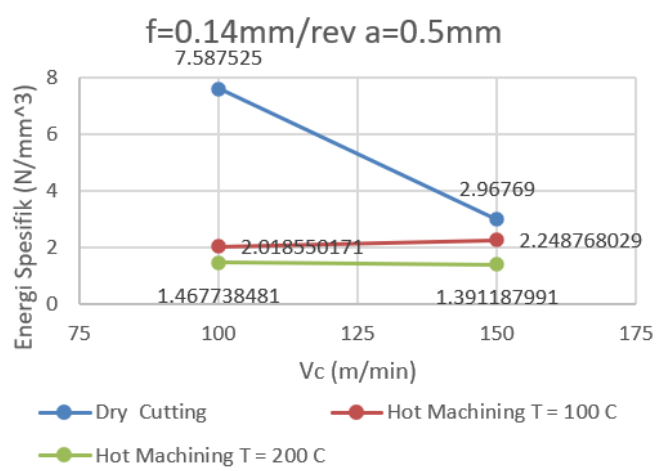

Figure 4. Graph of cutting specific energy to cutting speed with a feed rate of $0.14 \mathrm{~mm} / \mathrm{rev}$ and depth of cut of $0.5 \mathrm{~mm}$

At a feed rate of $0.0875 \mathrm{~mm} / \mathrm{rev}$ with a depth of cut in 1 $\mathrm{mm}$, the graph also shows a decrease in the specific energy value of the cut with increasing cutting speed. However, in hot machining conditions with a heating temperature of $150^{\circ} \mathrm{C}$ at a cutting speed of $125 \mathrm{~mm} / \mathrm{min}$ to $150 \mathrm{~m} / \mathrm{min}$, the graph shows the increasing specific cutting energy. 


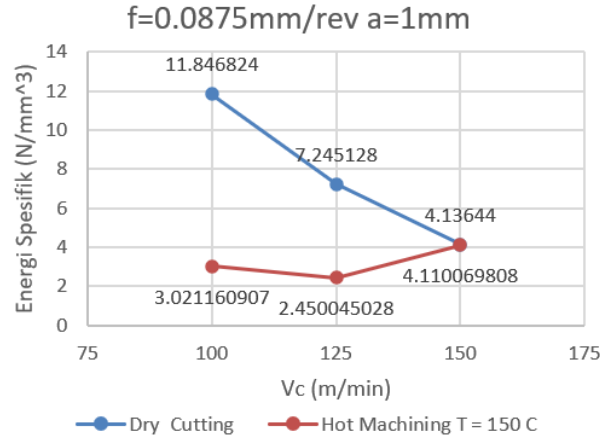

Figure 5. Graph of specific energy of cutting to cutting speed with a feed rate of $0.0875 \mathrm{~mm} / \mathrm{rev}$ and a depth of $1 \mathrm{~mm}$

For a comparison of the specific energy of cutting value, against various cutting speeds $(\mathrm{Vc})$, with the same depth of cut (a) and feeding rate (f), the graph shows a decrease in the specific energy of cutting for each increase in cutting speed $(\mathrm{Vc})$. The use of highspeed machining results in a lower specific energy of cutting due to the increase in cutting speed [8].

In the five graphs above, it can also be seen that using the hot machining method produces a smaller specific energy value than using the dry cutting method. This is caused by heat which reduces the value of the hardness and strength of the material. Very intense local thermal energy input by an appropriate heat source, drastically reducing the strength of the material when heated above a certain temperature, base on the properties of the workpiece material [9].

Table 2. Surface Roughness

\begin{tabular}{cccccc}
\hline No. & $\mathbf{V c}$ & $\mathbf{f}$ & $\mathbf{a}$ & $\mathbf{T}$ & $\mathbf{R a}$ \\
\hline 1 & 100 & 0.035 & 0.5 & 100 & 1.1822 \\
2 & 150 & 0.035 & 0.5 & 100 & 0.6289 \\
3 & 100 & 0.14 & 0.5 & 100 & 1.4667 \\
4 & 150 & 0.14 & 0.5 & 100 & 1.2556 \\
5 & 100 & 0.035 & 0.5 & 200 & 0.6767 \\
6 & 150 & 0.035 & 0.5 & 200 & 1.0167 \\
7 & 100 & 0.14 & 0.5 & 200 & 1.0467 \\
8 & 150 & 0.14 & 0.5 & 200 & 1.28 \\
9 & 100 & 0.0875 & 1 & 150 & 1,5233 \\
10 & 150 & 0.0875 & 1 & 150 & 0.9533 \\
11 & 125 & 0.0875 & 1 & 150 & 0.9289 \\
12 & 100 & 0.035 & 0.5 & 24 & 1.1467 \\
13 & 150 & 0.035 & 0.5 & 24 & 0.4533 \\
14 & 100 & 0.14 & 0.5 & 24 & 1.0611 \\
15 & 150 & 0.14 & 0.5 & 24 & 0.655 \\
16 & 100 & 0.0875 & 1 & 24 & 1.4217 \\
17 & 150 & 0.0875 & 1 & 24 & 1.0392 \\
18 & 125 & 0.0875 & 1 & 24 & 0.5856 \\
\hline & & & & &
\end{tabular}

\subsection{Specific Energy of Cutting to Surface Roughness Based on Feed Rate}

To get the chart below, the feed rate parameters are used with a value of $0.035 \mathrm{~mm} / \mathrm{rev}$ and $0.14 \mathrm{~mm} / \mathrm{rev}$ with constant cutting speed and depth of cut.

The two graphs below show the effect of specific cutting energy on surface roughness based on feed rate, where the graph shows that the greater the feed rate, the greater the resulting surface roughness. This shows that the surface roughness, and the feed rate are directly proportional but inversely related to the specific cutting energy. This means that the greater the feeding motion, the greater the value of the surface roughness during the turning process, but the smaller the specific energy value of the cutting.

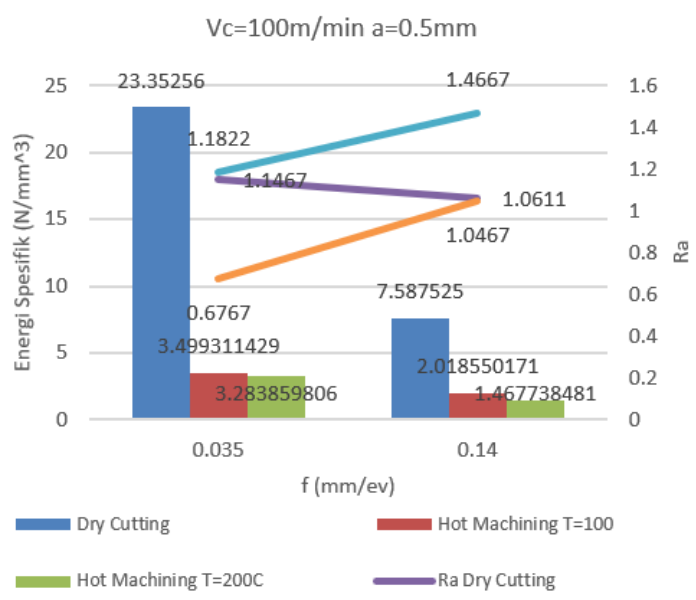

Figure 6. Effect of specific energy of cutting on surface roughness based on feed rate at cutting speed $100 \mathrm{~m} /$ $\min$

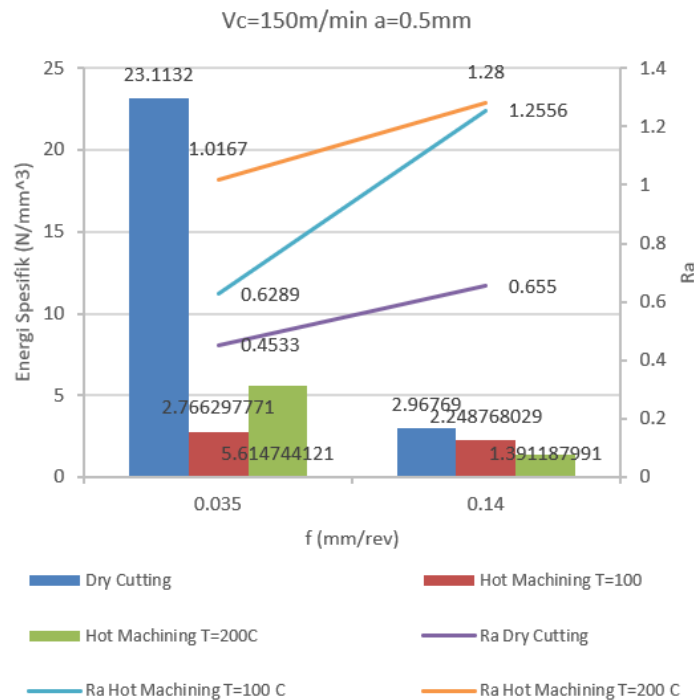

Figure 7. The effect of specific energy of cutting on surface roughness based on the feed rate at cutting speed $150 \mathrm{~m} / \mathrm{min}$ 


\subsection{Specific Cutting Energy Against Surface Roughness Based on Cutting Speed}

For a feed rate $0.035 \mathrm{~m} / \mathrm{rev}$, and depth of cut 0.5 $\mathrm{mm}$, the graph shows that the greater the cutting speed, the smaller the surface roughness value obtained, but in hot machining conditions with a heating temperature of $200^{\circ} \mathrm{C}$, the graph shows an increase in the roughness value with increasing the cutting speed. This also occurs at $0.14 \mathrm{~mm} / \mathrm{rev}$ feed rate, and $0.5 \mathrm{~mm}$ depth of cut.

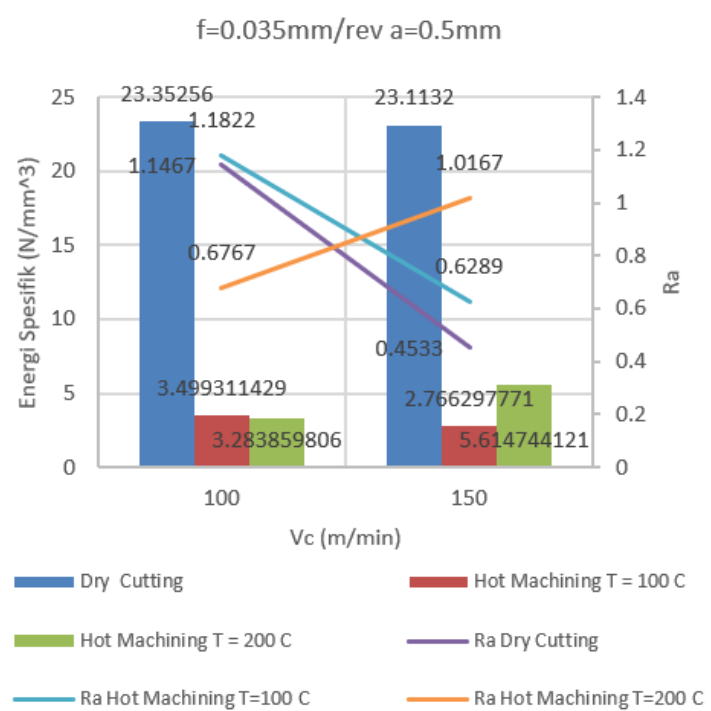

Figure 8. The effect of specific cutting energy on surface roughness based on cutting speed at $0.035 \mathrm{~mm} /$ rev feed rate
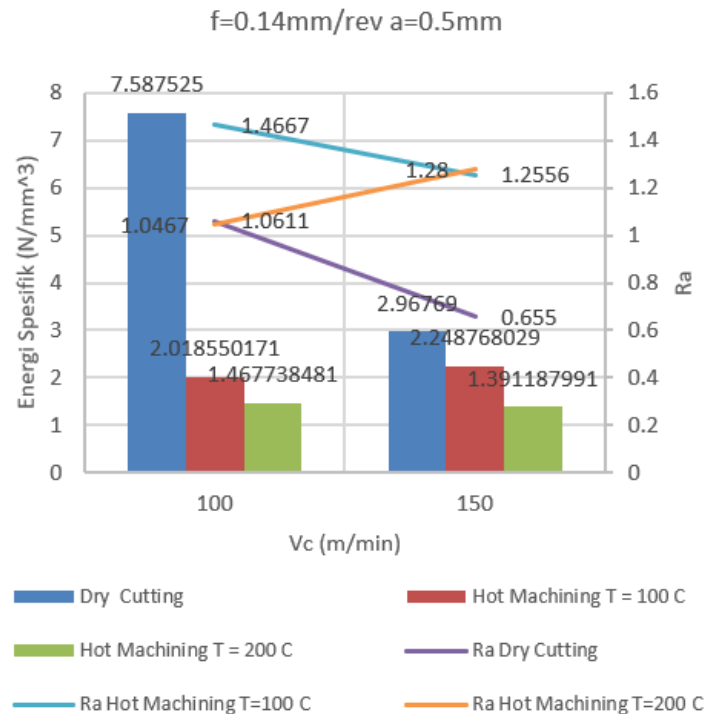

Figure 9. The effect of specific energy of cutting on surface roughness based on cutting speed at $0.14 \mathrm{~mm} / \mathrm{rev}$ feed rate

At feed rate $0.0875 \mathrm{~mm} / \mathrm{rev}$ and depth of cut $1 \mathrm{~mm}$, the graph shows a decrease in the roughness value at a cutting speed of $100 \mathrm{~m} / \mathrm{min}$ towards a cutting speed of $125 \mathrm{~m} / \mathrm{min}$. After that, it increases at a speed of $150 \mathrm{~m} /$ min. This applies to dry cutting and hot machining conditions with a heating temperature of $150 \mathrm{C}$.

$f=0.0875 \mathrm{~mm} /$ rev $a=1 \mathrm{~mm}$

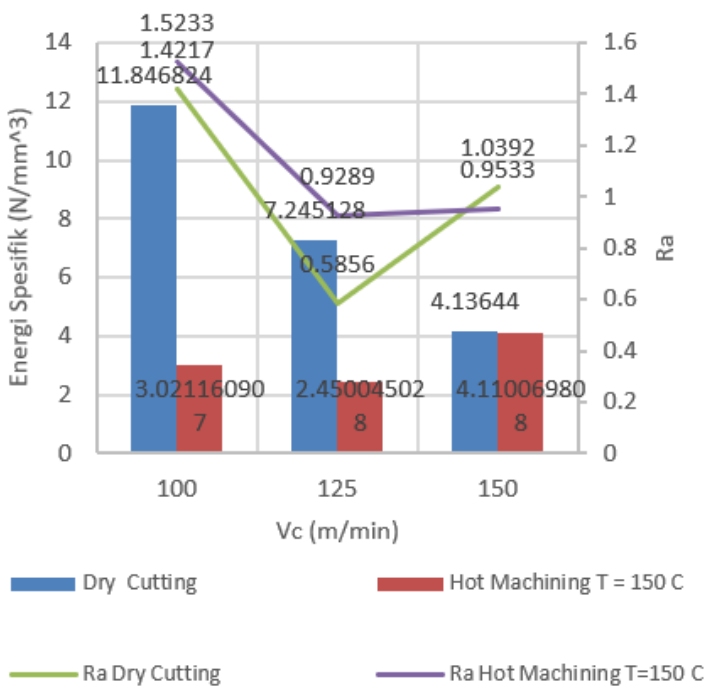

Figure 10. The effect of specific cutting energy on surface roughness based on cutting speed at $0.875 \mathrm{~mm} / \mathrm{rev}$ feed rate

This shows the value of the surface roughness value with the specific cutting energy is directly proportional to and inversely proportional to the cutting speed. This means that the greater the cutting speed value, the smaller the surface roughness value during the turning process, and the smaller the specific cutting energy value.

\section{CONCLUSION}

From the research, the following conclusions were obtained :

- From the theoretical calculation, it is found that the greater the cutting speed $(\mathrm{Vc})$, the specific energy of cutting, and the surface roughness will decrease.

- Feeding motion affects the specific energy value of cutting and surface roughness, the greater the feeding motion, the smaller the specific cutting energy obtained, but the surface roughness value increases.

- The hot machining method affects the value of the specific energy of cutting. The specific energy value of the cutting using the hot machining method is smaller than the dry cutting method.

\section{ACKNOWLEDGMENTS}

This research was supported by Sriwijaya University, and the author thank to Engineering Faculty and LPPM of Sriwijaya University. 


\section{REFERENCES}

[1] K. A. Al-Ghamdi, A. Iqbal, and G. Hussain, "Machinability comparison of AISI 4340 and Ti6Al-4V under cryogenic and hybrid cooling environments: A knowledge engineering approach," Proc. Inst. Mech. Eng. Part B J. Eng. Manuf., vol. 229, no. 12, pp. 2144-2164, 2015.

[2] V. A. Balogun and P. T. Mativenga, "Impact of un-deformed chip thickness on specific energy in mechanical machining processes," J. Clean. Prod., vol. 69, pp. 260-268, 2014.

[3] Jayal, A.D. et al., 2010. CIRP Journal of Manufacturing Science and Technology Sustainable manufacturing: Modeling and optimization challenges at the product, process and system levels. , 2, pp.144-152. https://doi.org/10.1016/j.cirpj.2010.03.006

[4] M. M. Patel and S. B. Patel, "A Review on Optimization of Hot Machining Process," vol. 1, no. 4, pp. 72-74, 2016.

[5] Mehul Gosaia, Sanket N. Bhavsarb, 2016, Experimental Study on Temperature Measurement in Turning Operation of Hardened Steel (EN 36), Procedia Technology
23 (2016), pp 311-318, 3rd International Conference on Innovations in Automation and Mechatronics Engineering ICIAME 2016. https://doi.org/10.1016/j.protcy.2016.03.032

[6] M. P. Groover, Fundamental of Modern Manufacturing Material, Processes, and System Fifth Edition. 2012.

[7] V. A. Balogun and P. T. Mativenga, "Specific Energy Based Characterization of Surface Integrity in Mechanical Machining," Procedia Manuf., vol. 7, pp. 290-296, 2017 https://doi.org/10.1016/j.promfg.2016.12.072

[8] E. A. Rahim, A. A. Rahim, M. R. Ibrahim, and Z. Mohid, "Experimental Investigation of Supercritical Carbon Dioxide (SCCO2) Performance as a Sustainable Cooling Technique," Procedia CIRP, vol. 40, pp. 637-641, 2016. https://doi.org/10.1016/j.procir.2016.01.147

[9] A. K. M. Nurul Amin and T. L. Ginta, HeatAssisted Machining, vol. 11. Elsevier, 2014. 